\title{
Advanced phases and reduced amplitudes are suggested to characterize the daily rest-activity cycles in depressed adolescent boys
}

Merikanto, Ilona

2017-06

Merikanto , I , Partonen , T , Paunio , T , Castaneda , A E, Marttunen , M \& Urrila , A S 2017

, ' Advanced phases and reduced amplitudes are suggested to characterize the daily rest-activity cycles in depressed adolescent boys ' , Chronobiology International, vol. 34 , pÿno. 7 , pp. 967976 . https://doi.org/10.1080/07420528.2017.1332072

http://hdl.handle.net/10138/310857

https://doi.org/10.1080/07420528.2017.1332072

acceptedVersion

Downloaded from Helda, University of Helsinki institutional repository.

This is an electronic reprint of the original article.

This reprint may differ from the original in pagination and typographic detail.

Please cite the original version. 
Advanced phases and reduced amplitudes are suggested to characterize the daily rest-activity cycles in depressed adolescent boys

Ilona Merikanto ${ }^{1,2}$, Timo Partonen $^{1}$, Tiina Paunio ${ }^{3,4}$, Anu E. Castaneda ${ }^{5}$, Mauri Marttunen ${ }^{1,4}$, Anna S. Urrila ${ }^{1,4^{*}}$

${ }^{1}$ National Institute for Health and Welfare, Department of Public Health Solutions, Mental Health Unit, Helsinki, Finland

${ }^{2}$ Orton Orthopaedics Hospital, Helsinki, Finland

${ }^{3}$ National Institute for Health and Welfare, Department of Health, Genetics and Biomarkers Unit, Helsinki, Finland

${ }^{4}$ University of Helsinki and Helsinki University Hospital, Department of Psychiatry, Helsinki, Finland ${ }^{5}$ National Institute for Health and Welfare, Department of Welfare, Equality and Inclusion Unit, Helsinki, Finland

\section{*Corresponding author:}

Anna S. Urrila, National Institute for Health and Welfare, Department of Health, Mental Health Unit, P.O. Box 30, 00271 Helsinki, Finland, Tel.: +358-40-351 8547, E-mail: anna.urrila@helsinki.fi 


\section{ABSTRACT}

Self-reported eveningness has been previously associated with depressed mood among adults and adolescents. Here we study how circadian indicators based on actigraphic data differ between depressed and healthy adolescent boys. Our sample consisted of 17 medication-free adolescent boys, aged 14.5 to 17.5 years, of which eight had depressive disorder and were currently depressed and nine were healthy comparison participants. Psychiatric assessment was conducted by diagnostic interviews and complemented with observer-rating and self-rating scales. Actigraphic data were collected with wrist actigraphs for a minimum period of 25 consecutive days (range of 25 to 44 days). The behavioral trait of morningness-eveningness was measured with the 19-item Horne-Östberg Morningness-Eveningness Questionnaire. Based on the self-report the depressed boys were more prone to eveningness than healthy controls, but based on the actigraphic data they had earlier phases especially on school days and lower activity levels especially on weekends. On weekends the depressed boys showed a greater shift towards latertimed phases than healthy controls. Our results confirm a mismatch of the subjective morningness-eveningness preference (late-preference) and the objective rest-activity rhythm (early-prone) during school days in depressed adolescent boys.

Key words: actigraphy, adolescence, circadian, depression, diurnal, youth 


\section{Introduction}

Individuals differ in their daily timing of physiological functions and activity patterns, which determines the individual chronotype of the person. Individual chronotypes can be classified into an earlier-timed Morning-type, an Intermediate-type, or a later-timed Evening-type (Horne and Östberg, 1976) on a dimensional trait of morningness-eveningness behavior (Duffy et al., 1999, 2001). Age and physiological development influence this circadian preference. During adolescence, there is a higher tendency towards eveningness than towards earlier-timed daily rhythms, whereas tendency towards morningness appears to increase with aging (Broms et al., 2014; Merikanto et al., 2012; Roenneberg et al., 2004).

Disturbances of the circadian system have been suggested to play an important role in the pathogenesis of affective disorders (Wulff et al., 2010). Eveningness and tendency towards depression have been associated together in population-based, representative epidemiological studies among both young adults and adults (Chelminski et al., 1999; Drennan et al., 1991; Merikanto et al., 2013, 2015, 2016). The evening chronotype has been regarded as a vulnerability marker to emotional difficulties among adolescents also under experimental conditions (Dagys et al., 2012). It has been postulated that the normal phase delay occurring in adolescence is amplified along with depression (Urrila et al., 2015).

Spontaneous rest-activity cycles, reflecting the circadian rhythms, can be recorded for extended time periods with wrist actigraphy. Actigraphy has been regarded more reliable in detecting the circadian rhythms than daily sleep logs which rely on self-disclosure, and more reliable than observations which capture only short periods of time such as polysomnographic recordings (Ancoli-Israel et al., 2003). Earlier findings of actigraphy studies among adolescents with depressive disorder have pointed at blunted circadian rhythms, being characterized by lower 
activity levels and lower circadian amplitudes as compared to healthy controls (Armitage et al., 2004; Finazzi et al, 2010; Teicher et al.,2013), and potentially at a delayed sleep phase (Robillard et al., 2013). Findings seem, however, to depend on age, gender, and features of depression: these findings have been more marked in adolescents as compared to children (Teicher et al., 1993), girls may show this effect at an earlier age than boys (Armitage et al., 2004), and a delayed sleep phase seems more common among bipolar vs. unipolar depression (Robillard et al., 2013) as well as with a longer duration of illness (Grierson et al., 2016; Naismith et al., 2012).

Here, we studied how the daily rest-activity cycles differ between healthy and depressed nonmedicated adolescent boys, aged 14-17 years, by collecting and analyzing actigraphic data from a period consisting of at least 25 consecutive days. Based on earlier reports, we hypothesized that depressed adolescent boys would show lower activity levels and delayed phases as compared to healthy controls.

\section{Materials and methods}

\section{Participants}

The sample consisted of eight depressed adolescent boys as cases and nine healthy comparison participants as controls. The patients were outpatients originally recruited from the Helsinki University Central Hospital, Department of Adolescent Psychiatry outpatient units for a project on sleep in adolescent depression $(n=10)$. The healthy controls were recruited via advertisements in a newspaper for the hospital staff $(n=10)$. One patient from the original sample did not meet the diagnostic criteria for depressive disorder and was thus excluded from the analyses. Further, a sufficient amount of actigraphic data were not received from one participant in the healthy 
control group and for one participant in the patient group due to poor compliance to the study protocol, leaving a total of 17 participants for analysis.

All subjects underwent thorough clinical examination, which included a psychiatric interview, routine morning blood samples, and structural brain MRI taken at the Helsinki University Central Hospital. For all participants, exclusion criteria included current use of any medication, chronic somatic illness, mental retardation, age of over 17.5 or under 14.5 years, substance abuse or dependence, any contraindication for brain magnetic resonance imaging, and insufficient skills of the Finnish language. In the patient group, a principal DSM-IV axis I diagnosis other than depressive disorder led to exclusion.

Both the participants and their parents or legal guardians gave a written informed consent for study participation. The study protocol was approved by the ethics committee of the Helsinki University Central Hospital (24.8.2011; 137/13/03/03/2011 §183).

\section{$\underline{\text { Psychiatric assessment }}$}

The participants were assessed for the current and lifetime episodes of DSM-IV axis I disorders with the Schedule for Affective Disorders and Schizophrenia for School-Age Children - Present and Lifetime version (K-SADS-PL) (Kaufman et al., 1997). All the interviews were performed by the same clinician (A.S.U.), and the diagnoses were confirmed in consensus meetings with a senior clinician (M.M.). The DSM-IV axis I diagnoses for the patients are shown in Table 1. The global assessment of functioning scale (GAF, with the numeric range of 0 to 100 ) was used according to the DSM-IV guidelines to assess the overall psychosocial functioning as part of the DSM-IV axial diagnostic procedure (American Psychiatric Association, 1994). 
The severity of depressive symptoms was further assessed with the 21-item Beck Depression Inventory (BDI-21) (Beck et al., 1961), and the Hamilton Depression Rating Scale (HDRS) (Hamilton, 1960), both of which have been successfully applied to adolescent samples (Brooks and Kutcher, 2001; Clarke et al., 2005; Emslie et al., 2007; Marton et al., 1991; Mufson et al., 2004; Urrila et al., 2012). The participants also filled in the Alcohol Use Disorder Identification Test (AUDIT) (Saunders et al., 1993), the Beck Anxiety Inventory (BAI) (Beck et al., 1988), the Pediatric Daytime Sleepiness Scale (PDSS) (Drake et al., 2003), and the Athens Insomnia Scale (AIS) (Soldatos et al., 2000) to complement the psychiatric assessment. The detailed characteristics are shown in Table 2.

\section{Self-reported circadian preference}

Circadian phase preference was measured with the Morningness-Eveningness Questionnaire (MEQ) (Horne and Östberg, 1976). MEQ scores have a range from 16 to 68, and lower scores indicate more preference to evening activities. The scores of 41 and below indicate "evening types", scores between 42 and 58 "intermediate types", and scores of 59 and above "morning types".

\section{Actigraphy}

The participants were instructed to wear wrist actigraphs (Actiwatch-Plus ${ }^{\circledR}$, Cambridge Neurotechnology Ltd, Cambridge, UK) on their non-dominant wrist for four consecutive weeks. Actigraphic data were collected in 60-second epochs over the recording period. For all the participants and all the variables, the primary period for analysis consisted of 23 consecutive days, being equal to the fast Fourier transformation period of 32,768 minutes, and starting on Monday whenever possible. As exceptions, for one patient the analyzed period started on Thursday, and for one healthy control on Friday. 
The data were analyzed using the software provided by the manufacturer (Actiwatch Activity \& Sleep Analysis, version 5.43), and the following variables were calculated: 1) variables measuring the level of rest-activity: amplitude (the range of activity levels across the 24-hour period), relative amplitude (M10 minus L5 divided by M10 plus L5), activity during the five hours of lowest activity (L5), activity during the 10 most active hours (M10), and average activity counts (separately during school days and weekends); 2) variables measuring the phase of the rest-activity rhythm: the onset of five hours of lowest activity (L5 onset), the onset of 10 most active hours (M10 onset), and cosine peak (separately during school days and weekends, indicating the timing of peak activity during the circadian period); 3) variables measuring the period of the rest-activity rhythm: period (the first peak of the daily rest-activity cycles in fast Fourier transformation, FFT, with the one-hour display), and peak correlation (indicating the length of the circadian period, with the one-minute resolution); 4) variables measuring the stability of the rest-activity rhythm: interdaily stability, and intradaily variability.

In addition to the main analyses, additional confirmatory non-parametric circadian rhythm analyses (NPCRA) were made to benefit from the maximum length of each actigraphic recording, which ranged between 25 to 44 days among the participants (see Supplementary Tables 1 and 2).

\section{$\underline{\text { Statistical analyses }}$}

Statistical analyses were performed with the SPSS version 21 (IBM, Chicago, IL). Descriptive characteristics were compared between the patients and healthy controls with chi-squared tests for the categorical variables, and with the one-way analysis of variance (ANOVA) for the scale variables (Please see Table 2 for detailed description of the descriptive characteristics). The mean values of the circadian estimates were compared between the patients and healthy controls by 
using the one-way ANOVA. Linear regression analyses were performed to estimate the association of the group status (the depressed vs. healthy participants) with the circadian variables. First, the crude (univariate) associations were analyzed. Second, the models were controlled for the age at the start of the recording, body-mass index $\left(\mathrm{BMI} ; \mathrm{kg} / \mathrm{m}^{2}\right)$, and serum testosterone level. BMI was included in the covariates, as it is associated with depressive symptoms, late bedtimes and sleep problems in adolescents (Arora et al., 2015; Golley et al., 2013; Sjöberg et al., 2005; Snell et al., 2007). Age and testosterone level were included in the covariates, as age and rise in testosterone levels may associate with depression and circadian rhythms in adolescents (Angold et al., 1998, 1999; Crowley et al. 2014). Finally, the models were controlled for the age at the start of the recording, BMI, testosterone level, and chronotype. The self-reported chronotype and objectively measured rest-activity cycles are not completely interchangeable: the first describes the circadian preference in the timing of daily activities and behaviors, whereas the latter shows the actualized individual sleep-wake rhythm. Therefore, the self-reported chronotype was included in the covariates, as it is associated with depressive symptoms (Merikanto et al., 2013, 2015). In these analyses, the healthy controls were the reference category. A value of $p<0.05$ was generally considered as statistically significant. To assess the statistical strength of the results, a Bonferroni correction was applied when multiple variables were assessed to test a single hypothesis.

\section{Results}

\section{$\underline{\text { Sample characteristics }}$}

The participants were on average 16.0 years old (with a standard deviation of 0.9 ) at the start of the actigraphic recordings. Of the patients, seven suffered from their first depressive episode, and one from his second depressive episode (Table 1). The severity of depression was moderate on 
average, and the mean ( \pm s.d.) length of the current depressive episode was $53( \pm 52)$ weeks. None of the patients suffered from bipolar disorder or manifested psychotic features. No clear atypical or melancholic features of depressive disorder were evident among the patients. Two patients presented with comorbid DSM-IV axis I disorders: one with anxiety disorder, and one with disruptive behavior disorder. No DSM-IV axis I diagnoses were found among the healthy controls. As expected, the patients had higher scores on the BDI-21, HDRS, and AIS, and lower scores on the GAF than healthy controls, while there were no differences in the age, BMI, testosterone level, BAI, AUDIT, or PDSS scores (Table 2).

All adolescents were free of psychotropic and other medication during the whole study period. The depressed adolescents received treatment as usual at the adolescent psychiatric outpatient unit (individual and family appointments), but none of them received formal psychotherapy. No structural pathologies were found in their brain anatomy according to magnetic resonance imaging, and the absence of somatic conditions was confirmed based on the clinical assessment and routine blood samples. All subjects consumed daily less than three cups of coffee or the equivalent amount of other caffeinated products.

During the study, the participants were attending, depending on their age, either the compulsory basic comprehensive school (eighth or ninth grade), general upper secondary school (first or second grade), or vocational school (first or second grade). The majority of the participants lived with both of their parents. In both the patient and the healthy control groups, one participant lived with a single parent, and additionally, in the patient group, one participant lived in a children's home, and one participant lived every alternate week with his mother and father.

\section{Circadian phase preference}


There were no Morning-types in the sample, so it consisted of only two chronotypes, the Intermediate-type and the Evening-type. The Evening-type was significantly more common among the patients ( $71 \%$ within the group) than among healthy controls ( $22 \%$ within the group). In line with this, the MEQ score was significantly lower among the patients than healthy controls, indicating a greater preference towards the eveningness among the patients (Table 2).

\section{Actigraphy}

Level of rest-activity. The average activity counts on weekends was lower among the patients than healthy controls in all the regression models by both FFT and NPCRA period (Table 4 and Supplementary Table 2) and in ANOVA by using the maximum recording period of NPCRA (Supplementary Table 1). The number of average activity counts on school days was lower among the patients than healthy controls in the full regression model 3 when the maximum recording period of NPCRA was analyzed (Supplementary Table 2). The activity during the 10 most active hours (M10) was lower among the patients than healthy controls in the full regression model 3 by FFT period (Table 4) and in all the regression analysis models analyzed using the maximum recording period of NPCRA (Supplementary table 2). The amplitude was lower among the patients in the full regression model 3 by FFT period (Table 4). Using a Bonferroni corrected $p$-value of $p<0.0083$, only the average activity on weekends remained statistically significant (in tables 4 and supplementary table 2 regarding regression models 3 , where $p=0.002$ and $p=0.003$ respectively). No statistically significant findings were seen in the relative amplitude and the activity during the five hours of lowest activity (L5).

Phase of the rest-activity rhythm. The onset of 10 most active hours (M10 onset) and school day cosine peak were earlier among the patients than healthy controls in ANOVA, and in all the 
regression models analyzed, both by FFT and NPCRA period (Tables 3 and 4; Supplementary Tables 1 and 2). These results were most robust in the full model 3 by FFT period after controlling for the age at the start of the actigraphic recordings, BMI, testosterone level, and chronotype (Table 4). Using a Bonferroni corrected $p$-value of $p<0.0125$, most of these results remained statistically significant $(p<0.01)$ : the cosine peak in ANOVA (table 3 ), and both the cosine peak and the M10 onset in all the regression models (in tables 4 and supplementary table 2). No statistically significant findings were seen in the $L 5$ onset and the cosine peak weekends.

Period of the rest-activity rhythm. The analysis of peak correlation in the full regression model 3 by FFT period, adjusted with self-reported chronotype, indicated an earlier activity peak among the patients than healthy controls (Table 4). No statistically significant findings were seen in the period.

Stability of the rest-activity rhythm. No statistically significant findings were observed in inter-daily stability or intra-daily variability in any of the analyses.

\section{Discussion}

To summarize, we found advanced phases, reduced activity amplitudes, and shorter periods of rest-activity cycles among depressed adolescent boys as compared to healthy controls.

Our findings on lower activity levels and reduced amplitudes among depressed adolescent boys as compared to healthy controls are in line with our hypothesis and in agreement with previous studies pointing towards weakened circadian rhythms among depressed adolescents (Armitage et al., 2004; Teicher et al., 1993). Compared to earlier studies with shorter actigraphy measurement periods (five consecutive days in Armitage et al., 2004; 72 hours in Teicher et al., 1993), our longer 
measurement period enabled us, however, also to separate school days and weekdays and extend previous findings.

In our sample, the most active 10 hours of the day overlapped with the period spent at school (usually between 8 a.m. and 16 p.m. in Finland) more clearly among the patients (10 most active hours starting from 9:30 a.m.) than among the healthy controls (starting at 11:47 a.m.) who were thus more active also in the evenings. Concerning the earlier-timed activity in particular during school days, it is plausible that the patients were trying to manage with school, but were missing some extra-curricular activities. The healthy controls also had higher activity levels especially during weekends than patients, which might indicate having more social contacts and hobbies.

Our findings herein provide support for the hypothesis of circadian rhythms dysregulation in depression, which proposes that a breakdown in circadian rhythms is linked to and might even cause depression (Goodwin et al., 1982). Our results indicated a discrepancy between the subjectively reported preference to daily activities (later in depressed adolescent boys) and the objectively measured phase of rest-activity rhythms (earlier in depressed adolescent boys vs. healthy controls). This mismatch might pose a disadvantage for depressed adolescents. Our results are in line with the view that depressive episodes advance the timing of the rest-activity cycles in relation to the remaining circadian rhythms, thus suggesting a weakening of the coupling to the principal pacemaker (Daimon et al., 1992). However, the findings remain conflicting to date, some studies suggesting a delayed objectively measured phase (Lewy, 2010; Robillard et al., 2014; Xian et al., 2015). Further, healthy evening-typed persons ("night owls") as compared with morningtyped persons ("morning larks"), all aged 19 to 64 years, had a higher ratio of phase advancing to phase delaying by light exposure, indicating a longer circadian period in evening-typed persons (Emens et al., 2009). 
The analysis of peak correlation, yielding the circadian period length, indicated a shorter period among the patients than healthy controls, but only when the analysis was adjusted with the selfreported circadian preference. Interestingly, the shift towards more later-timed peaks in activity during weekends than on school days was greater in the patients than healthy controls. This shift was almost three hours towards the evening among the patients, while it was just one hour towards the evening among the healthy controls. It is likely that the timing of the highest activity peaks on weekends reflects more closely the natural chronotype of the patients than the timing of the peak activity on school days, which is dictated by school schedule and might be especially challenging for depressed individuals.

The strengths of this study include the homogeneous nature of the sample in terms of age and gender, the lack of psychotropic and other medication use among all participants, the detailed psychiatric evaluation, the low amount of comorbid psychiatric disorders, and the long actigraphy recording period.

Limitations of the study include most notably the small sample size, which allows us to make only preliminary conclusions on the results, and which limits more specific subgroup analyses. As the sample size in this study is rather small and we included multiple variables for testing each of the two a priori hypotheses, our study should be regarded as exploratory and the results as preliminary. Our statistically strongest results survived, however, a conservative Bonferronicorrection for multiple testing: the depressed boys showed consistently advanced phases (as measured by M10 onset and cosine peak on weekdays) in all regression analyses with both the FFT and the NPCRA period even at a significance level of $p<0.01$ (Table 4 and supplementary table 2). Our finding on a reduced amplitude and in particular that of a shorter period should, however, be 
more cautiously assessed, since they were statistically much weaker. Further studies with larger sample sizes are therefore needed to confirm and extend our results.

A further limitation of our study is that we assessed only the rest-activity cycles, not other circadian measures such as cortisol, melatonin, or temperature rhythms. In addition, it would be important in the future to include repeated mood assessments along the actigraphy recording period. It could also be argued that including only patients without psychotropic treatments can present a selection bias, but then again psychotropic medication can affect the actualized sleep rhythm (Ferguson, 2001; Armitage et al., 1997; Golub et al. 2016) and thus might skew the effect between depression and circadian rhythm. Excluding female participants from the sample, on the one hand, limits the generalizability of the findings to depressed adolescent girls, but on the other hand, also excluded the potential confounding effects of the menstrual cycle phase on the measurement of circadian rhythms (Dzaja et al., 2005). Depressed adolescent girls and boys have also been reported to differ in their circadian rest-activity cycles and should thus be studied separately (Armitage et al., 2004). Furthermore, Morning-types were not represented in our sample, which thus limits the comparisons made between different circadian preference types.

To conclude, our results suggest that depressed adolescent boys report higher tendency towards eveningness, but have earlier phases especially on school days, as well as lower activity levels especially on weekends, and possibly generally shorter circadian periods than healthy controls. Our results confirm earlier findings on disrupted circadian rhythms in depressed adolescent boys. The conflicting results between subjective and objective measures of circadian rhythms may point towards a wearing mismatch of subjective circadian phase preference (late-preference) and actualized objectively measured rest-activity (early-prone) in depressed adolescent boys. Paying attention to increasing the total daytime activity (e.g., by means of favoring sports or other 
activities), to the regularity of rest-activity cycles (e.g., by means of regular sleep schedules or meals), to suitable exposure to time-givers (e.g., by means of light exposures), and to the appropriate timing of these events are potential measures to synchronize the external and internal clocks in depressed adolescents, and to avoid mismatch and misalignment. Further research efforts are required to address the benefits and disadvantages of these interventions in the treatment of adolescent depression.

\section{Declaration of Interest statement}

This work was supported by the Academy of Finland (grant number 276612), a special federal grant (grant number TYH 2013342), the Emil Aaltonen Foundation, the Finnish Medical Foundation, the Finnish Brain Foundation, the Orion Farmos Research Foundation, the Päivikki and Sakari Sohlberg Foundation, and the Foundation for Psychiatric Research. None of the funding sources had a role in study design, data collection, data analysis or interpretation, writing of the paper, or the decision to submit the manuscript for publication. The authors report no conflicts of interest and the authors alone are responsible for the content and writing of the paper.

\section{References}

American Psychiatric Association (1994). Diagnostic and statistical manual of mental disorders, fourth ed. (DSM-IV). American Psychiatric Association, Washington DC. 
Ancoli-Israel S, Cole R, Alessi C, Chambers M, Moorcroft W, Pollak CP. (2003). The role of actigraphy in the study of sleep and circadian rhythms. Sleep 26:342-392.

Angold A, Costello EJ, Worthman CM. (1998). Puberty and depression: the roles of age, pubertal status and pubertal timing. Psychol Med. 28:51-61.

Angold A, Costello EJ, Erkanli A, Worthman CM. (1999). Pubertal changes in hormone levels and depression in girls. Psychol Med. 29:1043-1053.

Armitage R, Hoffmann R, Emslie G, Rintelman J, Moore J, Lewis K. (2004). Rest-activity cycles in childhood and adolescent depression. J Am Acad Child Adolesc Psychiatry 43:761-769.

Armitage R, Emslie G, Rintelmann J. (1997) The effect of fluoxetine on sleep EEG in childhood depression: a preliminary report. Neuropsychopharmacology 17:241-5.

Arora T, Taheri S. (2015). Associations among late chronotype, body mass index and dietary behaviors in young adolescents. Int J Obes (Lond) 1:39-44.

Beck AT, Ward CH, Mendelson M, Mock J, Erbaugh J. (1961). An inventory for measuring depression. Arch Gen Psychiatry 4:561-571.

Beck AT, Epstein N, Brown G, Steer RA. (1988). An inventory for measuring clinical anxiety: psychometric properties. J Consult Clin Psychol. 56:893-897. 
Broms U, Pitkäniemi J, Bäckmand H, Heikkilä K, Koskenvuo M, Peltonen M, Sarna S, Vartiainen E, Kaprio J, Partonen T. (2014). Long-term consistency of diurnal-type preferences among men. Chronobiol Int. 31:182-188.

Brooks SJ, Kutcher S. (2001). Diagnosis and measurement of adolescent depression: a review of commonly utilized instruments. J. Child Adolesc Psychopharmacol. 11:341-376.

Chelminski I, Ferraro FR, Petros TV, Plaud JJ. (1999). An analysis of the "eveningness-morningness" dimension in "depressive" college students. J Affect Disord. 52:19-29.

Clarke G, Debar L, Lynch F, Powell J, Gale J, O'Connor E, Ludman E, Bush T, Lin EH, Von Korff M, Hertert S. (2005). A randomized effectiveness trial of brief cognitive-behavioral therapy for depressed adolescents receiving antidepressant medication. J Am Acad Child Adolesc Psychiatry $44: 888-898$.

Crowley SJ, Van Reen E, LeBourgeois MK, Acebo C, Tarokh L, Seifer R, Barker DH, Carskadon M. (2014). A longitudinal assessment of sleep timing, circadian phase, and phase angle of entrainment across human adolescence. PLoS One 9, e112199.

Dagys N, McGlinchey EL, Talbot LS, Kaplan KA, Dahl RE, Harvey AG. (2012). Double trouble? The effects of sleep deprivation and chronotype on adolescent affect. J Child Psychol Psychiatry $53: 660-667$. 
Daimon K, Yamada N, Tsujimoto T, Takahashi S. (1992). Circadian rhythm abnormalities of deep body temperature in depressive disorders. J Affect Disord. 26:191-198.

Drake C, Nickel C, Burduvali E, Roth T, Jefferson C, Badia P. (2003). The pediatric daytime sleepiness scale (PDSS): sleep habits and school outcomes in middle-school children. Sleep $26: 455-458$.

Drennan MD, Klauber MR, Kripke DF, Goyette LM. (1991). The effects of depression and age on the Horne-Ostberg morningness-eveningness score. J Affect Disord. 23:93-98.

Duffy J, Dijk D, Hall E, Czeisler C. (1999). Relationship of endogenous circadian melatonin and temperature rhythms to self-reported preference for morning or evening activity in young and older people. J Investig Med. 47:141-150.

Duffy JF, Rimmer DW, Czeisler CA. (2001). Association of intrinsic circadian period with morningness-eveningness, usual wake time, and circadian phase. Behav Neurosci. 115:895-899.

Dzaja A, Arber S, Hislop J, Kerkhofs M, Kopp C, Pollmächer T, Polo-Kantola P, Skene DJ, Stenuit P, Tobler I. (2005). Women's sleep in health and disease. J Psychiatr Res. 39:55-76.

Emens JS, Yuhas K, Rough J, Kochar N, Peters D, Lewy AJ. (2009). Phase angle of entrainment in morning- and evening-types under naturalistic conditions. Chronobiol Int. 26:474-493. 
Emslie GJ, Findling RL, Yeung PP, Kunz NR, Li Y. (2007). Venlafaxine ER for the treatment of pediatric subjects with depression: results of two placebo-controlled trials. J Am Acad Child Adolesc Psychiatry 46:479-488.

Ferguson, J.M. (2001). SSRI antidepressant medications: Adverse effects and tolerability. Prim. Care Companion. J Clin. Psychiatry 3(1):22-27.

Finazzi ME, Mesquita ME, Lopes JR, Fu LI, Oliveira MG, Del Porto JA. (2016). Motor activity and depression severity in adolescent outpatients. Neuropsychobiology 61:33-40.

Golley RK, Maher CA, Matricciani L, Olds TS. (2013). Sleep duration or bedtime? Exploring the association between sleep timing behaviour, diet and BMI in children and adolescents. Int J Obes (Lond). 37:546-551.

Golub MS, Hogrefe CE. (2016) Sleep disturbance as detected by actigraphy in pre-pubertal juvenile monkeys receiving therapeutic doses of fluoxetine. Neurotoxicol Teratol. 55:1-7.

Goodwin FK, Wirz-Justice A, Wehr TA. (1982). Evidence that the pathophysiology of depression and the mechanism of action of antidepressant drugs both involve alterations in circadian rhythms. Adv Biochem Psychopharmacol. 32:1-11.

Grierson AB, Hickie IB, Naismith SL, Hermens DF, Scott EM, Scott J. (2016). Circadian rhythmicity in emerging mood disorders: state or trait marker? Int J Bipolar Disord. 4:3. 
Hamilton M. (1960). A rating scale for depression. J Neurol Neurosurg Psychiatry 23:56-62.

Horne JA, Östberg O. (1976). A self-assessment questionnaire to determine morningnesseveningness in human circadian rhythms. Int J Chronobiol. 4:97-110.

Kaufman J, Birmaher B, Brent D, Rao U, Flynn C, Moreci P, Williamson D, Ryan N. (1997). Schedule for affective disorders and schizophrenia for school-age children-present and lifetime version (KSADS-PL): initial reliability and validity data. J Am Acad Child Adolesc Psychiatry 36:980-988.

Lewy AJ. (2010). Depressive disorders may more commonly be related to circadian phase delays rather than advances: time will tell. Sleep Med. 11:117-118.

Marton P, Churchard M, Kutcher S, Korenblum M. (1991). Diagnostic utility of the Beck Depression Inventory with adolescent psychiatric outpatients and inpatients. Can J Psychiatry 36:428-431.

Merikanto I, Kronholm E, Peltonen M, Laatikainen T, Lahti T, Partonen T. (2012). Relation of Chronotype to sleep complaints in the general Finnish population. Chronobiol Int. 29:311-317.

Merikanto I, Lahti T, Kronholm E, Peltonen M, Laatikainen T, Vartiainen E, Salomaa V, Partonen T. (2013). Evening types are prone to depression. Chronobiol Int. 30:719-725.

Merikanto I, Kronholm E, Peltonen M, Laatikainen T, Vartiainen E, Partonen T. (2015). Circadian preference links to depression in general adult population. J Affect Disord. 188:143-148. 
Merikanto I, Suvisaari J, Lahti T, Partonen T. (2016). Eveningness relates to burnout and seasonal sleep and mood problems among young adults. Nord J Psychiatry 70:72-80.

Mufson L, Dorta KP, Wickramaratne P, Nomura Y, Olfson M, Weissman MM. (2004). A randomized effectiveness trial of interpersonal psychotherapy fordepressed adolescents. Arch Gen Psychiatry 61:577-584.

Naismith SL, Hermens DF, Ip TK, Bolitho S, Scott E, Rogers NL, Hickie IB. (2012). Circadian profiles in young people during the early stages of affective disorder. Transl Psychiatry 2:e123.

Robillard R, Naismith SL, Rogers NL, Ip TK, Hermens DF, Scott EM, Hickie IB. (2013). Delayed sleep phase in young people with unipolar or bipolar affective disorders. J Affect Disord. 145:260-263.

Robillard R, Naismith SL, Smith KL, Rogers NL, White D, Terpening Z, Ip TK, Hermens DF, Whitwell B, Scott EM. (2014). Sleep-wake cycle in young and older persons with a lifetime history of mood disorders. PLoS One 9:e87763.

Roenneberg T, Kuehnle T, Pramstaller PP, Ricken J, Havel M, Guth A, Merrow M. (2004). A marker for the end of adolescence. Curr Biol. 14:R1038-R1039.

Saunders JB, Aasland OG, Babor TF, De la Fuente JR, Grant M. (1993). Development of the alcohol use disorders identification test (AUDIT): WHO collaborative project on early detection of persons with harmful alcohol consumption-II. Addiction 88:791-804. 
Sjöberg RL, Nilsson KW, Leppert J. (2005). Obesity, shame, and depression in school-aged children: a population-based study. Pediatrics 116:e389-e392.

Snell EK, Adam EK, Duncan GJ. (2007). Sleep and the body mass index and overweight status of children and adolescents. Child Dev. 78:309-323.

Soldatos CR, Dikeos DG, Paparrigopoulos TJ. (2000). Athens Insomnia Scale: validation of an instrument based on ICD-10 criteria. J Psychosom Res. 48:555-560.

Teicher MH, Glod CA, Harper D, Magnus E, Brasher C, Wren F, Pahlavan K. (1993). Locomotor activity in depressed children and adolescents: I. Circadian dysregulation. J Am Acad Child Adolesc Psychiatry 32:760-769.

Urrila AS, Karlsson L, Kiviruusu O, Pelkonen M, Strandholm T, Marttunen M. (2012). Sleep complaints among adolescent outpatients with major depressive disorder. Sleep Med. 13:816823.

Urrila AS, Paunio T, Palomäki E, Marttunen M. (2015). Sleep in adolescent depression: physiological perspectives. Acta Physiol. (Oxf). 213:758-777.

Wulff K, Gatti S, Wettstein JG, Foster RG. (2010). Sleep and circadian rhythm disruption in psychiatric and neurodegenerative disease. Nat Rev Neurosci. 11:589-599. 
Xian H, Gonzalez C, Deych E, Farris S, Ding J, Shannon W, McCall WV. (2015). Age-related effects on circadian phase in the sleep of patients with depression and insomnia. Behav Sleep Med.

$13: 208-216$. 


\section{Merikanto et al.}

Advanced phases, reduced amplitudes, and shorter periods are suggested to characterize the daily rest-activity cycles in depressed adolescent boys

Table 1. DSM-IV axis I diagnoses of the cases.

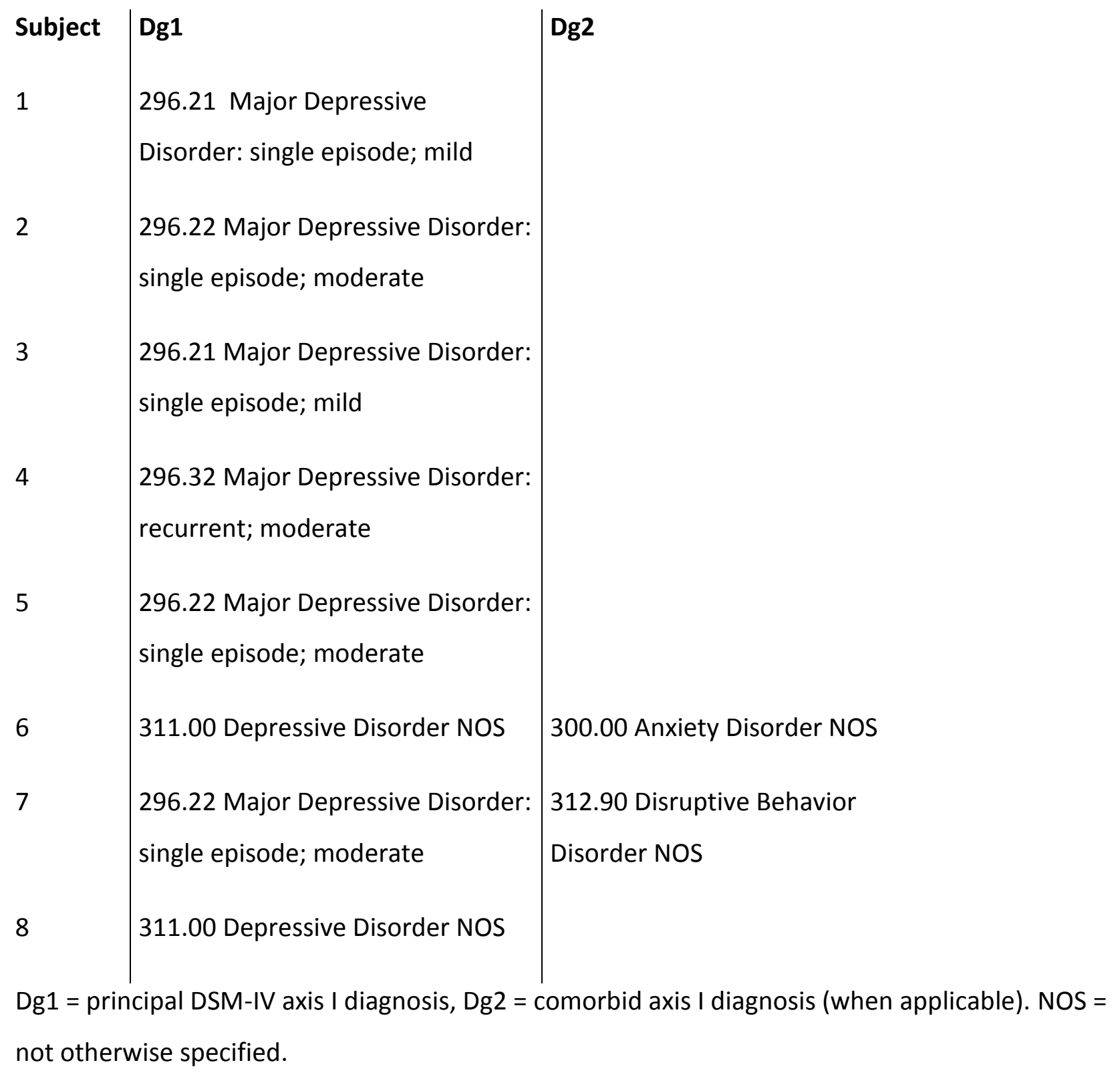




\section{Merikanto et al.}

Advanced phases, reduced amplitudes, and shorter periods are suggested to characterize the daily rest-activity cycles in depressed adolescent boys

Table 2. Descriptive information by subgroup.

Age at ACG start (years)

$\mathrm{BMI}$

\begin{tabular}{l|l} 
Chronotype * & Evening-type (\%)
\end{tabular} Intermediate-type (\%)

$\mathrm{MEQ}^{*}$

Serum testosterone level

$\mathrm{BDI}-21 * *$

HDRS****

BAI

AUDIT

PDSS

$\mathrm{GAF}^{* * * *}$

AIS**
Controls ( $\mathrm{N}=9$ )

$16.0 \pm 0.7$

$20.6 \pm 1.8$

22.2

77.8

$45.2 \pm 7.1$

$19.4 \pm 3.6$

$2.6 \pm 4.2$

$0.3 \pm 0.7$

$3.2 \pm 4.3$

$4.6 \pm 4.6$

$13.0 \pm 5.1$

$81.1 \pm 4.9$

$2.0 \pm 2.3$
Patients $(\mathrm{N}=\mathbf{8})$

$16.0 \pm 1.1$

$21.4 \pm 3.9$

71.4

28.6

$35.7 \pm 7.0$

$20.4 \pm 4.1$

$16.9 \pm 12.0$

$12.9 \pm 4.4$

$8.4 \pm 5.8$

$1.6 \pm 1.6$

$17.9 \pm 5.0$

$50.6 \pm 6.2$

$9.4 \pm 6.2$

$\mathrm{ACG}=$ actigraphy; $\mathrm{BMI}=$ body mass index; $\mathrm{MEQ}=$ Morningness - Eveningness Questionnaire; $\mathrm{BDI}-21$

= 21-item Beck Depression Inventory; HDRS = Hamilton Depression Rating Scale; BAI = Beck Anxiety Inventory; AUDIT = Alcohol Use Disorder Identification Test $;$ PDSS $=$ Pediatric Daytime Sleepiness Scale; GAF = Global Assessment of Functioning; AIS = the Athens Insomnia Scale. Values are expressed as mean \pm s.d., except for chronotype (\%). ${ }^{*} p<0.05 ;{ }^{* *} p<0.01 ;{ }^{* * *} p<0.001 ;{ }^{* * *} p$ $<0.0001$ in one-way ANOVA (scale variables) or chi-squared test (categorical variables). 


\section{Merikanto et al.}

Advanced phases, reduced amplitudes, and shorter periods are suggested to characterize the daily rest-activity cycles in depressed adolescent boys

Table 3. Results from ANOVA by using the FFT period ( 23 days).

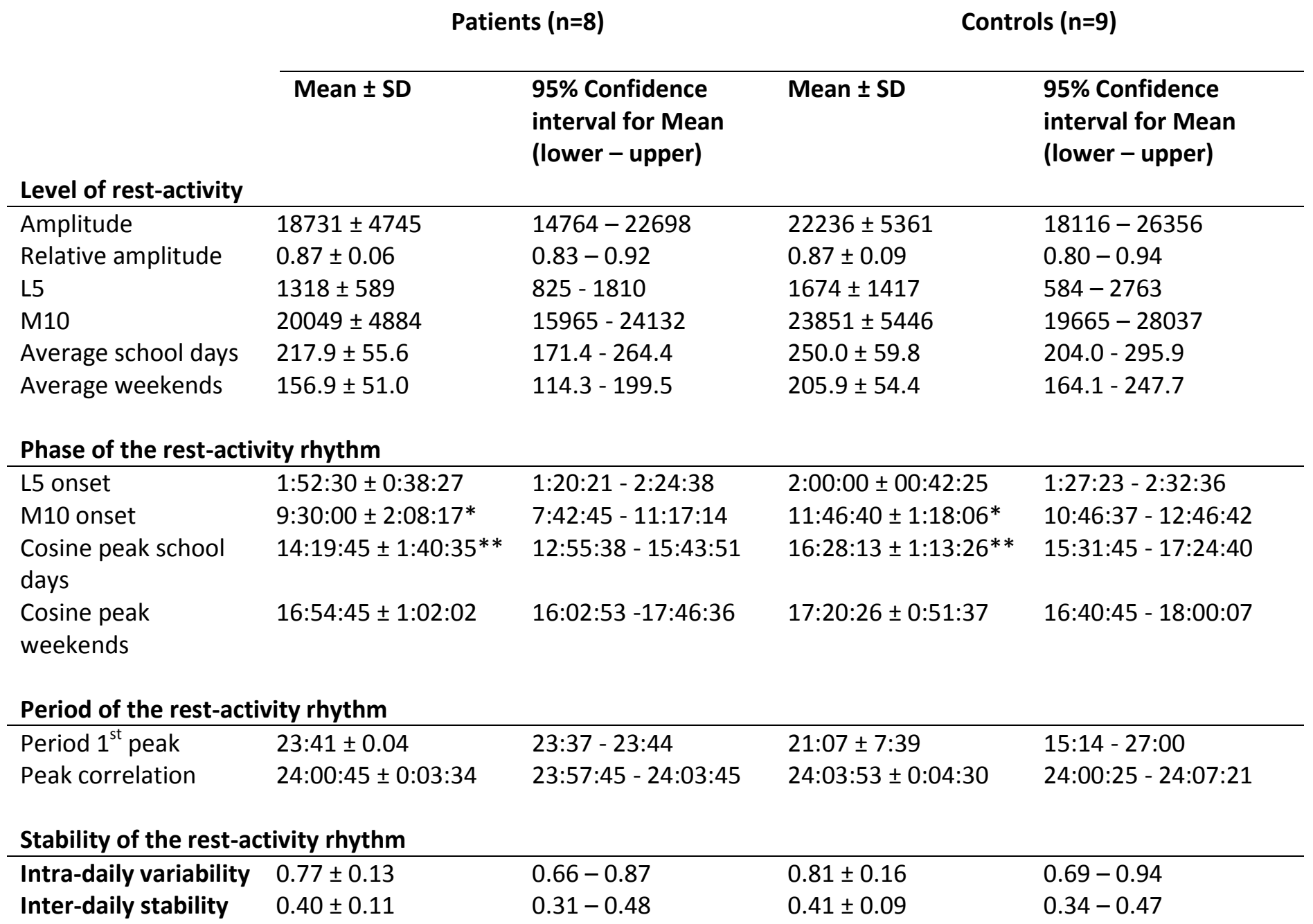

${ }^{*} p<0.05 ;{ }^{* *} p<0.01$ 
Merikanto et al.

Advanced phases, reduced amplitudes, and shorter periods are suggested to characterize the daily restactivity cycles in depressed adolescent boys

Table 3. Results from ANOVA by using the FFT period ( 23 days).

Patients $(n=8)$
Controls $(n=9)$

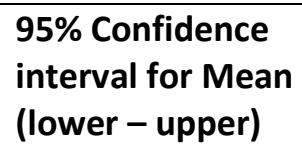

Level of rest-activity

Amplitude
Relative amplitude

L5

M10

Average school days

Average weekends

$18731 \pm 4745$
$0.87 \pm 0.06$

$1318 \pm 589$

$20049 \pm 4884$

$217.9 \pm 55.6$

$156.9 \pm 51.0$

$14764-22698$

$0.83-0.92$

$825-1810$

$15965-24132$

$171.4-264.4$

$114.3-199.5$
Mean \pm SD interval for Mean

(lower - upper)

Phase of the rest-activity rhythm

\begin{tabular}{lllll}
\hline L5 onset & $1: 52: 30 \pm 0: 38: 27$ & $1: 20: 21-2: 24: 38$ & $2: 00: 00 \pm 00: 42: 25$ & $1: 27: 23-2: 32: 36$ \\
$\begin{array}{l}\text { M10 onset } \\
\begin{array}{l}\text { Cosine peak school } \\
\text { days }\end{array}\end{array}$ & $9: 30: 00 \pm 2: 08: 17^{*}$ & $7: 42: 45-11: 17: 14$ & $11: 46: 40 \pm 1: 18: 06^{*}$ & $10: 46: 37-12: 46: 42$ \\
$\begin{array}{l}\text { Cosine peak } \\
\text { weekends }\end{array}$ & $16: 54: 45 \pm 1: 02: 02$ & $16: 02: 53-17: 46: 36$ & $17: 20: 26 \pm 0: 51: 37$ & $16: 40: 45-18: 00: 07$ \\
& & & &
\end{tabular}

Period of the rest-activity rhythm

\begin{tabular}{|c|c|c|c|c|}
\hline Period $1^{\text {st }}$ peak & $23: 41 \pm 0.04$ & $23: 37-23: 44$ & $21: 07 \pm 7: 39$ & $15: 14-27: 00$ \\
\hline Peak correlation & $24: 00: 45 \pm 0: 03: 34$ & $23: 57: 45-24: 03: 45$ & $24: 03: 53 \pm 0: 04: 30$ & $24: 00: 25-24: 07: 21$ \\
\hline \multicolumn{5}{|c|}{ Stability of the rest-activity rhythm } \\
\hline Intra-daily variability & $0.77 \pm 0.13$ & $0.66-0.87$ & $0.81 \pm 0.16$ & $0.69-0.94$ \\
\hline Inter-daily stability & $0.40 \pm 0.11$ & $0.31-0.48$ & $0.41 \pm 0.09$ & $0.34-0.47$ \\
\hline
\end{tabular}

${ }^{*} p<0.05 ;{ }^{* *} p<0.01$ 
Merikanto et al. Advanced phases, reduced amplitudes, and shorter periods are suggested to characterize the daily rest-activity cycles in depressed adolescent boys

Table 4. Results from linear regression by using the FFT period (23 days).

\begin{tabular}{|c|c|c|c|c|c|c|}
\hline & \multicolumn{2}{|l|}{ Model 1} & \multicolumn{2}{|l|}{ Model 2} & \multicolumn{2}{|l|}{ Model 3} \\
\hline & B & $\begin{array}{l}95 \% \mathrm{Cl} \text { (lower - } \\
\text { upper) }\end{array}$ & B & $95 \% \mathrm{Cl}$ (lower - upper) & B & $\begin{array}{c}95 \% \mathrm{Cl} \text { (lower - } \\
\text { upper) }\end{array}$ \\
\hline \multicolumn{7}{|l|}{ Level of rest-activity } \\
\hline Amplitude & -3505.0 & $-8052.0-1042.0$ & -3505.0 & $-8052.0-1042.0$ & $-4705.9 *$ & $-9030.8--381.0$ \\
\hline Relative amplitude & 0.002 & $-0.07-0.07$ & 0.002 & $-0.07-0.07$ & 0.004 & $-0.07-0.08$ \\
\hline L5 & -356.4 & $-1350.0-637.2$ & -356.4 & $-1350.0-637.2$ & -487.8 & $-1521.9-546.2$ \\
\hline M10 & -3802.6 & $-8446.8-841.6$ & -3802.6 & $-8446.8-841.6$ & $-5135.0 *$ & $-9446.4--823.6$ \\
\hline Average school days & -32.04 & $-83.82-19.74$ & -32.04 & $-83.82-19.74$ & -46.57 & $-94.98-1.84$ \\
\hline Average weekends & $-49.04 *$ & $-96.29--1.78$ & $-49.04 *$ & $-96.29--1.78$ & $-64.88 * *$ & $-106.04--23.72$ \\
\hline \multicolumn{7}{|c|}{ Phase of the rest-activity rhythm } \\
\hline L5 onset & -450.0 & $-2630.3-1730.3$ & -450.0 & $-2630.3-1730.3$ & -514.3 & $-2842.1-1813.6$ \\
\hline M10 onset & $-8200.0 * *$ & $-13812.5--2587.5$ & $-8200.0 * *$ & $-13812.5--2587.5$ & $-9485.7 * * *$ & $-14995.3--3976.1$ \\
\hline Cosine peak school days & $-7708.3^{* *}$ & $-12387.5--3029.1$ & $-7708.3^{* *}$ & $-12387.5--3029.1$ & $-8404.8 * * *$ & $-13238.7--3570.9$ \\
\hline Cosine peak weekends & -1541.7 & $-4586.2-1502.9$ & -1541.7 & $-4586.2-1502.9$ & -1595.2 & $-4848.5-1658.0$ \\
\hline \multicolumn{7}{|c|}{ Period of the rest-activity rhythm } \\
\hline Peak correlation & -188.3 & $-408.5-31.8$ & -188.3 & $-408.5-31.8$ & $-241.9 *$ & $-455.5--28.4$ \\
\hline Period $1^{\text {st }}$ peak & 9228.3 & $-8772.1-27228.8$ & 9228.3 & $-8772.1-27228.8$ & 9247.6 & $-9995.6-28490.8$ \\
\hline \multicolumn{7}{|c|}{ Stability of the rest-activity rhythm } \\
\hline Inter-daily stability & -0.01 & $-0.10-0.08$ & -0.01 & $-0.10-0.08$ & -0.03 & $-0.12-0.07$ \\
\hline Intra-daily variability & -0.04 & $-0.20-0.09$ & -0.04 & $-0.20-0.09$ & -0.03 & $-0.16-0.11$ \\
\hline
\end{tabular}


Model 1 crude (univariate); model 2 controlled for age at ACG, BMI, and testosterone level; model 3 controlled for age at ACG, BMI, testosterone level, and chronotype. Healthy controls as the reference category. $\mathrm{Cl}=$ Confidence interval for mean. ${ }^{*} p<0.05 ;{ }^{* *} p<0.01 ; * * * p$ $<0.001$. 
Merikanto et al. Advanced phases, reduced amplitudes, and shorter periods are suggested to characterize the daily rest-activity cycles in depressed adolescent boys

Supplementary Table 1. Results from ANOVA by using the maximum NPCRA period (25-44 days).

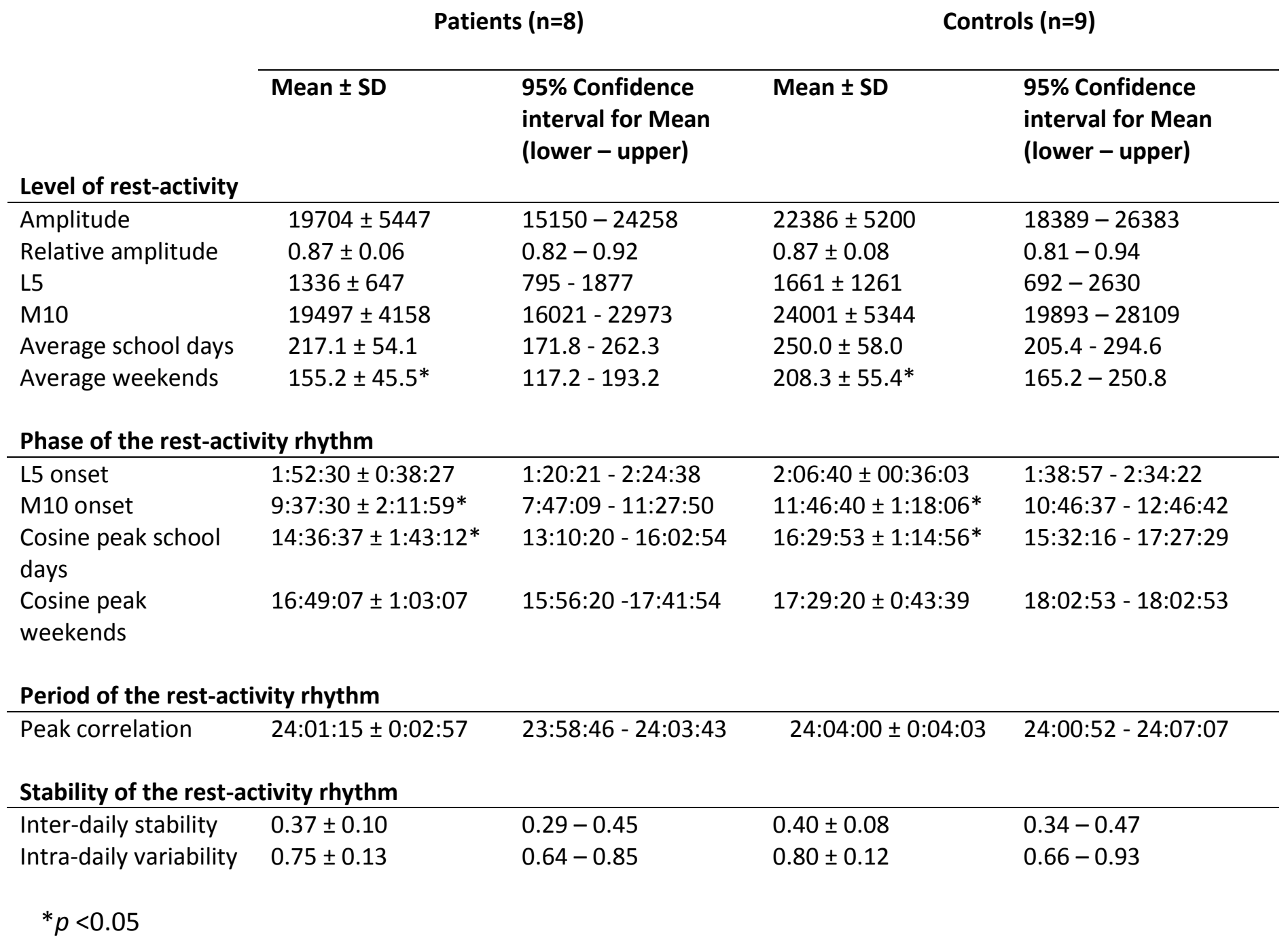


Merikanto et al. Advanced phases, reduced amplitudes, and shorter periods are suggested to characterize the daily rest-activity cycles in depressed adolescent boys

Supplementary Table 2. Results from linear regression by using the maximum NPCRA period (25-44 days).

\begin{tabular}{|c|c|c|c|c|c|c|}
\hline & \multicolumn{2}{|l|}{ Model 1} & \multicolumn{2}{|l|}{ Model 2} & \multicolumn{2}{|l|}{ Model 3} \\
\hline & B & $\begin{array}{l}\text { 95\% Cl (lower - } \\
\text { upper) }\end{array}$ & B & 95\% Cl (lower - upper) & B & $\begin{array}{c}95 \% \mathrm{Cl} \text { (lower - } \\
\text { upper) }\end{array}$ \\
\hline \multicolumn{7}{|l|}{ Level of rest-activity } \\
\hline Amplitude & -2682.0 & $-7438.6-2074.6$ & -2682.0 & $-7438.6-2074.6$ & -3722.7 & $-8430.1-984.6$ \\
\hline Relative amplitude & -0.002 & $-0.12-0.05$ & -0.002 & $-0.07-0.06$ & 0.001 & $-0.07-0.07$ \\
\hline L5 & -325.3 & $-1239.1-588.6$ & -325.3 & $-1239.1-588.6$ & -468.9 & $-1409.0-471.3$ \\
\hline M10 & $-4503.5^{*}$ & $-8821.9--185.2$ & $-4503.5^{*}$ & $-8821.9--185.2$ & $-5573.8 * *$ & $-9745.3--1402.4$ \\
\hline Average school days & -32.96 & $-83.27-17.35$ & -32.96 & $-83.27-17.35$ & $-48.49 *$ & $-93.98--3.01$ \\
\hline Average weekends & $-53.08 *$ & $-98.70--7.46$ & $-53.08 *$ & $-98.70--7.46$ & $-67.12 * *$ & $-108.42--25.82$ \\
\hline \multicolumn{7}{|c|}{ Phase of the rest-activity rhythm } \\
\hline L5 onset & -850.0 & $-2846.4-1146.4$ & -850.0 & $-2846.4-1146.4$ & -914.3 & $-3045.2-1216.6$ \\
\hline M10 onset & $-7750.0 * *$ & $-13476.8--2023.2$ & $-7750.0 * *$ & $-13476.8--2023.2$ & $-8971.4 * *$ & $-14662.4--3280.4$ \\
\hline Cosine peak school days & $-6795.8 * *$ & $-11587.0--2004.7$ & $-6795.8 * *$ & $-11587.0--2004.7$ & $-7519.1 * *$ & $-12463.6--2574.6$ \\
\hline Cosine peak weekends & -2412.5 & $-5291.3-466.3$ & -2412.5 & $-5291.3-466.3$ & -2685.7 & $-5721.6-350.1$ \\
\hline \multicolumn{7}{|c|}{ Period of the rest-activity rhythm } \\
\hline Peak correlation & -165.0 & $-357.8-27.8$ & -165.0 & $-357.8-27.8$ & -145.7 & $-348.7-57.3$ \\
\hline \multicolumn{7}{|c|}{ Stability of the rest-activity rhythm } \\
\hline Inter-daily stability & -0.04 & $-0.18-0.09$ & -0.04 & $-0.12-0.05$ & -0.05 & $-0.13-0.04$ \\
\hline Intra-daily variability & -0.05 & $-0.18-0.09$ & -0.05 & $-0.18-0.09$ & -0.04 & $-0.18-0.11$ \\
\hline
\end{tabular}

Model 1 crude (univariate); model 2 controlled for age at ACG, BMI, and testosterone level; model 3 controlled for age at ACG, BMI, testosterone level, and chronotype. Healthy controls as the reference category. $\mathrm{Cl}=$ Confidence interval for mean. ${ }^{*} p<0.05 ;{ }^{* *} p<0.01$. 